\title{
Genetic Characterization of Toxocara vitulorum in Turkey by Mitochondrial Gene Markers (cox1)
}

\author{
Bekir Oguz
}

\begin{abstract}
Background: Toxocara vitulorum is a involved in the Ascaridoidea family and is a large roundworm with a semi translucent, soft body surface and pinkish color. Female worms measure $8-30 \mathrm{~cm}$ in length, male worms $6-25 \mathrm{~cm}$. The major hosts of T. vitulorum are buffalo (Bubalus bubalis) and cattle (Bos species) in the humid tropics of Asia, Africa and South America. The diagnosis of $T$. vitulorum infections is usually made by observing characteristic eggs in routine fecal examination. Serological methods are also used to diagnose Toxocariasis. However, in recent years, PCR, a new generation molecular diagnostic method, has been used. The genetic structure of T. vitulorum is little known compared with data available from other parasites. The present sutudy was designed to determine the $T$. vitulorum isolates by the genetic characterization of the mitochondrial cytochrome c oxidase subunit I ( $\operatorname{cox} 1)$ gene.

Materials, Methods \& Results: Adult worms were collected from the feces of two calves (East Anatolian Red) during visits to the clinic at the Department of Internal Medicine of Van Yuzuncu Yil University, Faculty of Veterinary Medicine. Worms were washed thoroughly in $0.85 \%$ saline to remove any debris and fixed into $70 \%$ ethanol. After repeated and thoroughly washing the specimens, total genomic DNA of parasite extraction was performed be employing DNA extraction reagent kit (Thermo, GeneJET Genomic DNA Purification Kit) according to manufacturer's recommendations. After DNA amplification, a $446 \mathrm{bp}$ fragment of cox 1 of T. vitulorum were obtained in all three isolates. All generated sequences were registered in GenBank database with accession numbers including MG905159, MG911729 and MG911730. The cox1 of T. vitulorum examined differed from another two isolates extracted from Germany beef cattle (KY313642.1) and Sri Lanka buffalo calf (FJ664617.1) at NCBI database. The MEGA 7 software was employed to calculate intra-species distance and similarity. The intra-species distance rate and similarity among the isolates were 0.005 and $99.995 \%$, respectively. The cox 1 sequence of $T$. vitulorum did not differ from an isolate from Germany, but differed more from isolate from Sri Lanka. The phylogenetic tree that was constructed using the Neighbor-Joining (NJ) method. Bootstrap support (Bp) for ML trees was calculating 1000 bootstrap replicates. This results indicate that both the different species of Toxocara are host-specific and each member of the genus Toxocara spp. has a different about the molecular sequences. We used the phylogenies from the Maximum Parsimony (MP) method to construct another phylogenetic tree based on the cox1 (mtDNA) gene. The results again display that the cattle-calves (East Anatolian Red) isolates from Turkey homology with that obtained from the Germany beef cattle (accession no. KY313642.1).

Discussion: The genetic analysis of parasites is a crucial factor in terms of determining epidemiology and the control parasitic diseases of humans and animals. Toxocara vitulorum is the most common gastrointestinal helmints infecting ruminants particularly in tropical regions. Phylogenetic analysis revealed that $T$. vitulorum is $100 \%$ homology with related to sequence of T. vitulorum from Germany. The characterization of cox 1 region can provides a foundation for accurate identification of some helminth species using PCR. Even though the small sample size, the obtained results might provide useful information for further phylogenetic studies on the family Ascaridae.
\end{abstract}

Keywords: Toxocara vitulorum, phylogenetic analysis, Cox1, Turkey. 


\section{INTRODUCTION}

The genus Toxocara includes parasitic nematodes of human and animal public health significance, such as $T$. canis, T. cati, Toxascaris leonina, T. malaysiensis, and $T$. vitulorum [7]. Of these, Toxocara vitulorum is a nematod living in small intestines of especially at a young age (1-3 months) cattle, water buffalos, and zebu. This nematod is widely common in tropical and subtropical climatic regions including Turkey and its pathogenicity leads to serious economic losses. It has been reported that the galactogenic through is very important in the form of infection $[2,3]$. The family Ascaridae is competent of infecting humans, leading to ocular and visceral larva migrans. The role of T. vitulorum in toxocariasis in humans is still not understood, although $T$. vitulorum larvae were carried out in somatic migration experimental animals [13,17]. Even though $T$. vitulorum is one of the least discussed parasites on the determination of helminthic fauna of domestic animals in Turkey, previous epidemiological studies have indicated that infection rate is $0.3-29.0 \%$. This prevalence rate recorded in Turkey ruminants is not negligible compared with the rate of prevalence rates recorded in other countries $[1,9]$.

Currently, DNA techniques have used widely to the identification and genetic differentiation of T. vitulorum and other Toxocara species [6,7,10,12]. Various studies have demonstrated that some genetic regions, such as the mitochondrial (mt) DNA and nuclear ribosomal DNA (rDNA) could ensure reliable markers for determine the phylogenetic relationships among the Toxocara species $[16,19,20,22]$. However, to the best of our knowledge, no reports were available on genetic analysis in T. vitulorum in Turkey. This study is the first to investigate the phylogeny of Toxocara vitulorum using PCR-based methods of a mitochondrial gene of cox 1 in Turkey.

\section{MATERIALS AND METHODS}

\section{Sample collection and DNA extraction}

Three adult worms were collected from the feces of two cattle-calves (East Anatolian Red) during visits to the clinic at the Department of Internal Medicine of Yuzuncu Yil University, Faculty of Veterinary Medicine. Worms were washed thoroughly in $0.85 \%$ saline to remove any debris and fixed into $70 \%$ ethanol. All the worms samples were stored at $-20^{\circ} \mathrm{C}$ prior to examination. After repeated and thoroughly washing the specimens, total genomic DNA of parasite extrac- tion was performed be employing DNA extraction reagent kit (GeneJET Genomic DNA Purification Kit) ${ }^{1}$ according to manufacturer's recommendations. The extracts were kept below $-20^{\circ} \mathrm{C}$ until the PCR.

\section{PCR amplification}

A portion of the cox 1 was amplified by PCR with primers JB3 (5'-T TTTTTGGGCATCCTGAGGTTTAT-3') and JB4.5 (5'-TAAAGAAAGAACATAATGAAAATG-3'), amplifying 446 bp sequence [5]. PCR was carried out in a final volume of $25 \mu \mathrm{L}$, containing 7.5 $\mu \mathrm{L}$ DNase- and RNase-free steril distilled water $^{2}, 10 \mu \mathrm{L} 5 \mathrm{X}$ MyTaq Reaction buffer ${ }^{3}, 1 \mu \mathrm{L}$ of each primer (20 pmol), $5 \mu \mathrm{L}$ of template DNA (100-200 ng), and $0.5 \mu \mathrm{L}$ of TaqDNA polymerase $(1.25 \mathrm{IU})^{4}$. The PCR conditions were as follows: $5 \mathrm{~min}$ at $94^{\circ} \mathrm{C}$ (initial denaturation), 35 cycles of $30 \mathrm{~s}$ at $94^{\circ} \mathrm{C}, 45 \mathrm{~s}$ at $50^{\circ} \mathrm{C}$, $35 \mathrm{~s}$ at $72^{\circ} \mathrm{C}$, and finally $10 \mathrm{~min}$ at $72^{\circ} \mathrm{C}$ (final extension). The PCR products were separated on agarose gels $(1.5 \%)$, stained with ethidium bromide and visualized and photographed on an UV transilluminator.

\section{DNA sequence and phylogenetic analysis}

The PCR products were subjected to capillary electrophoretic separation in a specialized laboratory (Sentegen, Ankara, Turkey) and sequence analyses of the products were performed. The product of the positive one was recorded into the Genbank and accession number was obtained. Sequence data were compared with other ascarids available at NCBI (http://blast.ncbi.nlm.nih.gov/ Blast.cgi), while alignments and phylogenetic analysis were conducted using the software MEGA and Bioedit [8].

\section{RESULTS}

After DNA amplification, a 446 bp fragment of cox 1 of $T$. vitulorum were obtained in all three isolates (Figure 1). All generated sequences were registered in GenBank database with accession numbers including MG905159, MG911729 and MG911730. The cox1 of T. vitulorum examined differed from another two isolates extracted from Germany beef cattle (KY313642.1) and Sri Lanka buffalo calf (FJ664617.1) at NCBI database. The MEGA 7 software was employed to calculate intraspecies distance and similarity. The intra-species distance rate and similarity among the isolates were 0.005 and $99.995 \%$, respectively. The cox 1 sequence of $T$. vitulorum did not differ from an isolate from Germany, but differed more from isolate from Sri Lanka (4\%) [Figure 2]. The phylogenetic tree that was constructed using the 


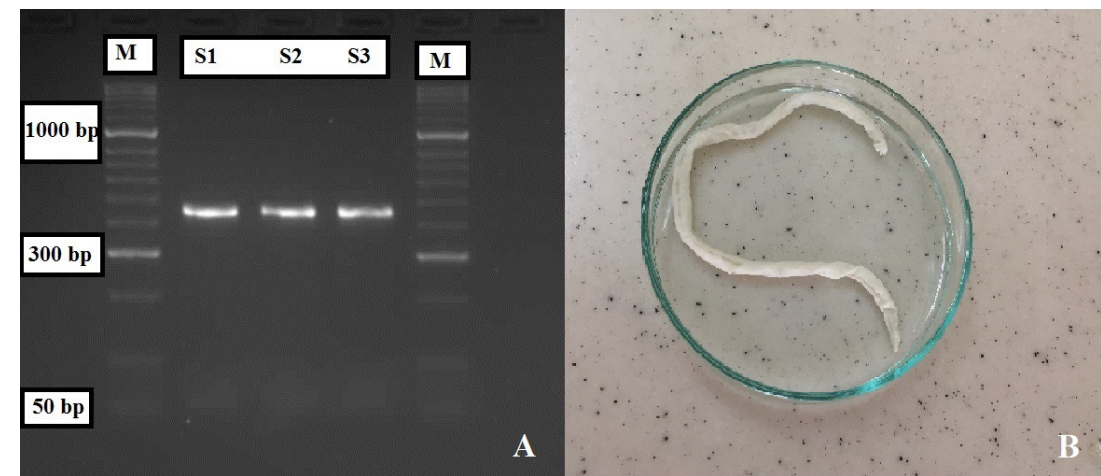

Figure 1. A- Specific PCR amplification of cox 1 of Toxocara vitulorum gene on $1.5 \%$ agarose gel. Lane M represents the $50 \mathrm{bp}$ DNA ladder. B- Macroscopic appearance of adult T. vitulorum.

Neighbor-Joining (NJ) method. Bootstrap support (Bp) for ML trees was calculating 1000 bootstrap replicates (Figure 3). These strains were T. vitulorum (accession no. KY313642.1, FJ664617.1), T. cati (KC200212.1, KC200211.1), A. suum (KT282029.1, KT282028.1), T. canis (AJ920056.1, AJ920055.1), T. malaysiensis (AJ920058.1, AJ920061.1), A. galli (GU138670.1, KP982856.1), P. equorum (KC998830.1, KC998829.1), A. lumbricoides (EU073134.1, EF150653.1). Diphyllobothrium latum (KU341712.1) was used as outgroups.
This results indicate that both the different species of Toxocara are host-specific and each member of the genus Toxocara spp. has a different about the molecular sequences. We used the phylogenies from the Maximum Parsimony (MP) method to construct another phylogenetic tree based on the cox 1 (mtDNA) gene. The results (Figure 4) again display that the cattle-calves (East Anatolian Red) isolates from Turkey homology with that obtained from the Germany beef cattle (accession no. KY313642.1).
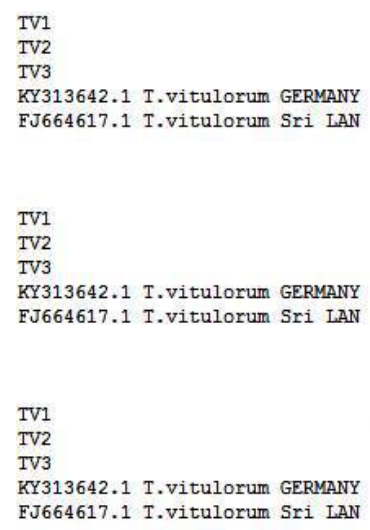

TV1

TV2

KY313642.1 T.vitulorum GERMANY FJ664617.1 T.vitulorum Sri LAN

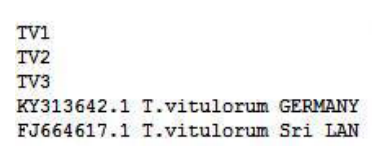

TV1

TV3

KY313642.1 T.vitulorum GERMANY FJ664617.1 T.vitulorum Sri LAN

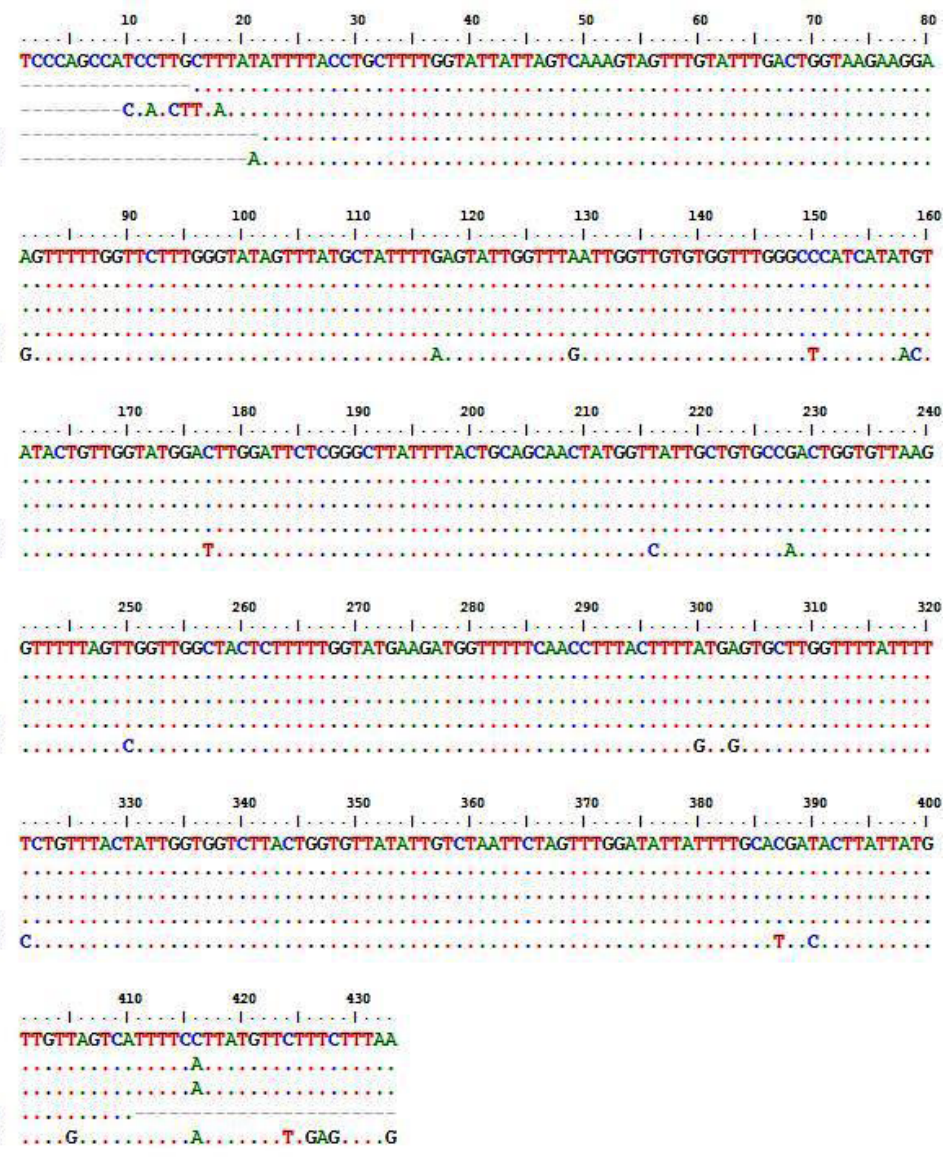

Figure 2. Alignment of sequence variation sites in Toxocara vitulorum cox 1 region compared with KY313642.1 and FJ664617.1 


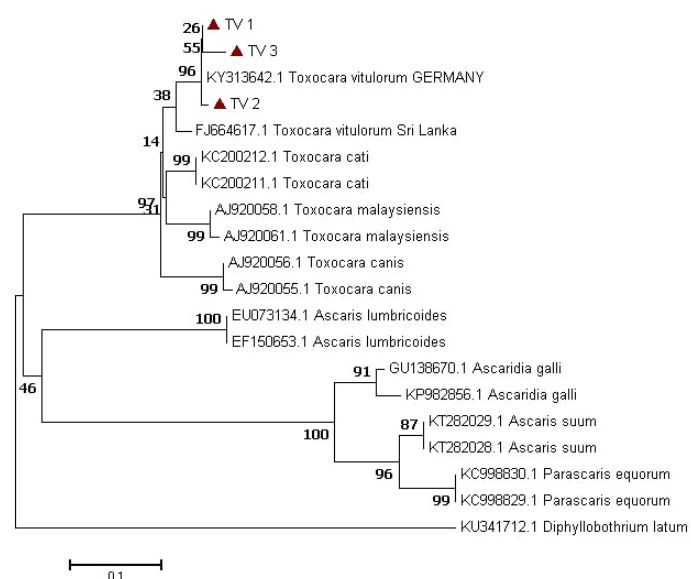

Figure 3. Distance phylogenetic tree constructed by an unrooted neighbourjoining method. The scale bar represents the estimated number of nucleotide substitutions per nucleotide site. The bootstrap values based on 1000 bootstrap replicates are indicated on each node.

\section{DISCUSSION}

The genetic analysis of parasites is a crucial factor in terms of determining epidemiology and the control parasitic diseases of humans and animals [9]. Toxocara vitulorum is the most common gastrointestinal helmints infecting ruminants particularly in tropical regions [18]. It has been reported that $T$. vitulorum is in many areas of Turkey, however it has been never survey on its genetic and phylogenetic status. In order that understand the genetic structure and certain phylogenetic position of $T$. vitulorum obtained from cattle in Turkey, genomic DNA was extracted and cox1gene was amplified.

Previous studies have commonly used the cox1 gene as genetic marker to identify Spirometra spp., Ascaris suum, Toxocara cati, Ancylostoma ceylanicum, Echinococcus granulosus [4,7,11,14,15]. Some authors have analysed the ribosomal (ITS1 and 18S) and mitochondrial (ND1) gene sequence of T. vitulorum. ITS-1 gene of Toxocara vitulorum can be suitable for diagnose and discriminate among different Toxocara spp. using polymerase chain reaction (PCR)-based techniques [16]. Li et al. [9] showed that for the ND1 gene, T. vitulorum was homologous to T. vitulorum (no. AJ937266) as previously reported by the same authors [10]. For the first time, Woodbury et al. [21] reported that T. vitulorum infection in bison calves in the province of Manitoba, Canada by sequencing partial internal
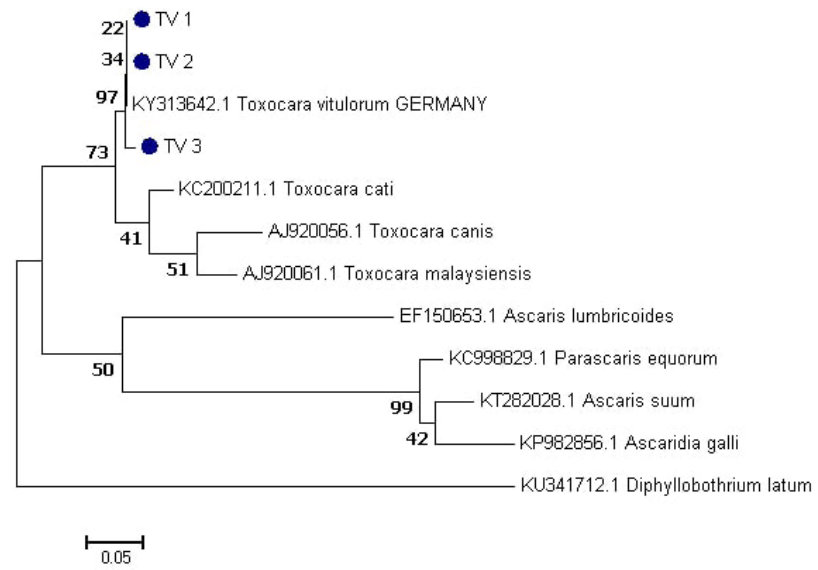

Figure 4. Phylogenetic relationships of Toxocara vitulorum isolates from Turkey using the mtDNA sequences (cox1) from the other ascaridoid nematodes conducted with Maximum Likelihood algorithm implemented in MEGA software v7. The bootstrap values based on 1000 bootstrap replicates are indicated on each node. Diphyllobothrium latum was used as outgroup.

transcribed spacer (ITS) 1 and 2. In contrast, only two sequences of cox 1 gene have been reported in T. vitulorum.

Given this utility of $\mathrm{mt}$ genomic datasets in the family Ascaridae, thus, further work should be done to constitute expanded $\mathrm{mt}$ (mitochondrial) datasets for this parasite. Phylogenetic classifications is a useful tool to gain information on evolutionary relationships among species. This study is the first phylogenetic analysis of Toxocara species from cattle-calves in Turkey. Phylogenetic analysis revealed that $T$. vitulorum is $100 \%$ homology with related to sequence of Toxocara vitulorum from Germany.

\section{CONCLUSIONS}

The characterization of cox 1 region can provides a foundation for accurate identification of some helminth species using PCR. Even though the small sample size, the obtained results might provide useful information for further phylogenetic studies on the family Ascaridae.

\section{MANUFACTURERS}

${ }^{1}$ Thermo Fisher Scientific. Waltham, MA, USA.

${ }^{2}$ BioBasic Inc. Markham, ON, Canada.

${ }^{3}$ Bioline Global Pty Ltd. Narellan, NSW, Australia.

${ }^{4}$ MBI Fermentas. St. Leon-Rot, Germany.

Declaration of interest. The authors report no conflicts of interest. The authors alone are responsible for the content and writing of the paper. 


\section{REFERENCES}

1 Abu-Elwafa S.A. \& Al-Araby M.A. 2008. Parasitic helminths among animals slaughtered at Dakahlia Province abattoirs. Mansoura Veterinary Medical Journal. 10(1): 93-104.

2 Avcioglu H. \& Balkaya I. 2001. Prevalence of Toxocara vitulorum in calves in Erzurum, Turkey. Kafkas Universitesi Veteriner Fakültesi Dergisi. 17(3): 345-347.

3 Aydin A., Göz Y., Yüksek N. \& Ayaz E. 2006. Prevalence of Toxocara vitulorum in Hakkâri Eastern Region of Turkey. Bulletin of the Veterinary Institute in Pulawy. 50: 51-54.

4 Boubaker G., Macchiaroli N., Prada L., Cucher M.A., Rosenzvit M.C., Ziadinov I. Deplazes P., Saarma U., Babba H., Gottstein B. \& Spiliotis M. 2013. A multiplex PCR for the simultaneous detection and genotyping of the Echinococcus granulosus complex. PLOS Neglected Tropical Diseases. 7(1): e2017.

5 Bowles J., Blair D. \& McManus D.P. 1992. Genetic variants within the genus Echinococcus identified by mitochondrial DNA sequencing. Molecular and Biochemical Parasitology. 54: 165-174.

6 Fogt-Wyrwas R., Mizgajska-Wiktor H., Pacon J. \& Jaroz W. 2013. Intraspecific variation between the ITS sequences of Toxocara canis, Toxocara cati and Toxascaris leonina from different host species in south-western Poland. Journal of Helminthology. 87: 432-442.

7 He X., Lv M.N., Liu G. \& Lin R.Q. 2018. Genetic analysis of Toxocara cati (Nematoda: Ascarididae) from Guangdong province, subtropical China. Mitochondrial DNA Part A: DNA Mapping, Sequencing, and Analysis. 29(1): 132-135.

8 Kumar S., Stecher G. \& Tamura K. 2016. Mega7: molecular evolutionary genetics analysis version 7.0 for bigger datasets. Molecular Biology and Evolution. 33: 1870-1874.

9 Li K., Lan Y., Luo H., Zhang H., Liu D., Zhang L., Gui R., Wang L., Shahzad M., Sizhu S., Li J. \& Chamba Y. 2016. Prevalence, Associated Risk Factors, and Phylogenetic Analysis of Toxocara vitulorum Infection in Yaks on the Qinghai Tibetan Plateau, China. The Korean Journal of Parasitology. 54(5): 645-652.

10 Li M.W., Zhu X.Q., Gasser R.B., Lin R.Q., Sani R.A., Lun Z.R. \& Jacobs D.E. 2006. The occurence of Toxocara malaysiensis in cats in China, confirmed by sequence-based analyses of ribosomal DNA. The journal Parasitology Research. 99(5): 554-557.

11 Luo H.Q., Zhang H., Li K., Lan Y.F., Shahzad M., Wang X.Q., Khalid M., Mujeeb R., Huang S.C., Li J.K. \& Yangzom Q.B. 2017. Molecular characterization of ascaris from Tibetan pigs by three mitochondrial markers of nad1, cox1 and cox2. Tropical Biomedicine. 34(3): 576-582.

12 Mikaeili F., Mirhendi H., Mohebali M., Hosseini M., Sharbatkhori M., Zarei Z. \& Kia E.B. 2015. Sequence variation in mitochondrial cox1 and nad1 genes of ascaridoid nematodes in cats and dogs from Iran. Journal of Helminthology. 89: 496-501.

13 Moyo D.Z. 2002. The migratory behaviour of Toxocara canis and Toxocara vitulorum in Balb/c mice. Zimbabwe Veterinary Journal. 33: 7-13.

14 Ngui R., Mahdya M.A.K., Chua K.H., Traub R. \& Lima Y.A.L. 2013. Genetic characterization of the partial mitochondrial cytochrome oxidase c subunit I ( $\operatorname{cox} 1)$ gene of the zoonotic parasitic nematode, Ancylostoma ceylanicum from humans, dogs and cats. Acta Tropica. 128: 154-157.

15 Petrigh R.S., Sciscia N.P., Denegri G.M. \& Fugassa M.H. 2015. Cox-1 gene sequence of Spirometra in Pampas foxes from Argentina. Helminthologia. 52(4): 355-359.

16 Sultan K., Omar M., Desouky A.Y. \& El-Seify M.A. 2015. Molecular and phylogenetic study on Toxocara vitulorum from cattle in the mid-Delta of Egypt. Journal of Parasitic Diseases. 39: 584-587.

17 Taylor M.R. 1984. The epidemiology of ocular toxocariasis. Journal of Helminthology. 75: 109-118.

18 Toparlak M., Deger S. \& Yılmaz H. 1989. Van yöresi sığırlarında Toxocara (Neoascaris) vitulorum enfeksiyonunun yayılış1. Ankara Üniversitesi Veteriner Fakültesi Dergisi. 36: 404-412.

19 Wickramasinghe S., Yatawara L., Rajapakse R.P.V.J. \& Agatsuma T. 2009. Toxocara vitulorum (Ascaridida: Nematoda): mitochondrial gene content, arrangement and composition compared with other Toxocara spp. Molecular and Biochemical Parasitology. 166: 89-92.

20 Wickramasinghe S., Yatawara L., Rajapakse R.P.V.J. \& Agatsuma T. 2009. Toxocara canis and Toxocara vitulorum: molecular characterization, discrimination, and phylogenetic analysis based on mitochondrial (ATP synthase subunit 6 and 12S) and nuclear ribosomal (ITS-2 and 28S) genes. The journal Parasitology Research. 104: 1425-1430. 
21 Woodbury M.R., Copeland S., Wagner B., Fernando C., Hill J.E. \& Clemence C. 2012. Toxocara vitulorum in a bison (Bison bison) herd from western Canada. The Canadian Veterinary Journal. 53: 791-794.

22 Zhu X.Q., Gasser R.B. \& Chilton N.B. 2001. Molecular approaches for studying ascaridoid nematodes with zoonotic potential, with an emphasis on Toxocara species. Journal of Helminthology. 75: 101-108. 